\title{
Mechanisms of aural encoding III: Distinctive features for vowels
}

\author{
B. DENNIS SALES, RALPH NORMAN HABER, ${ }^{2}$ AND R. ALLAN COLE 3 \\ UNIVERSITY OF ROCHESTER
}

To determine the processing of vowel sounds in short-term memory for a serial recall task. 100 Ss heard either a short string of isolated vowel sounds, or a string in which each of these same sounds was embedded between the consonants " $h$ " and " $d$." In contrast to findings by Wickelgren, neither an articulatory or an acoustic distinctive-feature analysis predicted the pattern of intrusion errors found. The overall recall of the different sounds was predicted by the ease with which they could be labelled for rehearsal. However, ease of labelling would not explain the pattern of intrusion errors, nor would any other analysis tried. These results are consistent with a coding model presented by Liberman et al (1967). Surprisingly, the patterns of intrusion errors were very similar whether the sounds were presented alone or embedded in words. The implications of these findings for distinctive feature theory and the encoding process are discussed.

Recent studies in short-term serial recall have supported the notion that verbal materials are encoded into short-term memory as a set of distinctive features. There have been two experimental procedures which validate this formulation. In the first procedure, Wickelgren $(1965,1966)$ measured the rank order of intrusion errors for consonants and for vowels. For consonants the intrusions are best described by a feature system in terms of voicing, nasality, place of articulation, and openness of the vocal tract. For vowels, the intrusions errors require only two features to explain them-the height of the tongue and its relative front-back position. Although an articulatory feature system is used by Wickelgren to explain his intrusion data, this does not indicate the encoding mechanism used, since there is a very close correspondence between articulation of a sound and the acoustic result (see Cole, Haber, \& Sales, 1908, for a brief discussion of this point).

The second procedure assumed that if sounds are confused because of feature-substitution. the number of confusions should be predictable by manipulating the feature environment in a recall list. Thus, confusions should be more likely the greater the number of distinctive features the items in a sequence share. Cole, Haber, and Sales (1968) tested this hypothesis by constructing lists of consonants whose itenus either shared very similar or relatively dissimilar distinctive features. Greater interference was found in the lists with similar features, especially when the distinctive feature common to the items was manner of articulation.

Both of these experiments support the value of a distinctivefeature model to analyze encoded sounds, especially consonants. The present study is designed to extend this work further with vowels. Vowel sounds are used that vary in their distinctive features, and in their ease of being labelled by an English speaker. They are presented for recall alone, or as vowels of monosyllabic words, each with the same consonantal environment.

The stimuli have been arranged to examine two possible hypotheses concerning the encoding of auditory material. The first hypothesis predicts that the pattern of intrusions will be explained by a distinctive feature analysis of intrusion errors. Sounds with more features in common should be more easily confused with each other. The other hypothesis states that sounds which can be easily labelled at the time they are encoded and rehearsed will be more resistant to intrusion errors during recall.

\section{METHOD}

Subjects

One hundred students from the University of Rochester introductory psychology course served as $\mathrm{Ss}$; their participation fulfilled a part of the course requirement. Each $S$ was pretested to ascertain whether he could discriminate and respond to each of the stimuli. Twelve potential Ss were eliminated for this reason. Testing was done individually in a session which lasted about 50 min.

\section{Stimuli}

Two sets of nine stimuli were used: the vowel sounds $/ \mathrm{i} /, / \mathrm{e} /$, $/ \mathrm{o} /, / \mathrm{u} /, / \mathrm{a} /, / \mathrm{D} /, / \mathrm{ae} /, / \mathrm{U} /, / \mathrm{I} /$ and the words heed, hade, hoed. who'd, hod, hawed, had, hood, hid. These stimuli were chosen for three reasons: (1) the vowel sounds in the words are similar to the vowel sounds when said in isolation: (2) the words varied in frequency from zero to very frequent (Thorndike \& Lorge, 1944); and $(3)$ the sounds could be differentiated by ease of labelling. The sounds $|\mathrm{i} /,| \mathrm{e} /$, and $/ 0 /$ (as in heed, hade. and hoed) correspond to the names of the English letters $E, A$, and $O$, and hence have highly overlearned labels available. The sounds $/ \mathrm{J} / \mathrm{a} / \mathrm{a}$, and $/ \mathbf{u} /$ (as in hawed, hod, and who'd), while not themselves letters, are often used as isolated words especially as mild explatives. Thus, they should not be as easily labelled as the first group of three, but certainly most Ss have had extensive experience with these sounds. Finally, the sounds $/ U / . / 1 /$. and $/ \mathrm{ae} /$ (as in hood, hid, and had) practically never occur in speech in isolation (even though in these examples they are the vowels of three familiar words) and hence should be very difficult to label.

\section{Procedure}

Stimulus lists were constructed such that sets of six of the nine vowel sounds were heard one at a time, or, sequences of seven of the nine words were presented. The rate was always one item per second. (Seven words were used in a list because we assumed that words would be slightly easier to recall than sounds in isolation, and we wanted overall performance on the two sets to be eluivalent.) Stimuli were randomly chosen from the nine for each sequence. with the recuirement that each sound or word appear in each position and with each other word an equal number of times.

Seventy-two sequences of six sounds, or seven words, were presented in a session. so that each sound occurred 48 times, or cach word 56 times. The $S$ heard either words or sounds but no $S$ had both conditions. The stimuli were recorded by a trained and highly skilled articulatory phonetician, and were presented on a Wollensak tape recorder. Responses were recorded on a second tilpe recorder.

In the sound condition, each of 50 Ss was instructed that he would hear lists of six sounds, and was asked to repeat the sounds of each list in the correct order after hearing them on the tape. After a list of six sounds was presented, there was a pause of $3 \mathrm{sec}$, after which a signal told $S$ to make his report. No explicit instructions about guessing were given, but $S$ was told to say "blank" if he could not remember a sound. He was allowed as much time to report as needed.

In the word condition, each of 50 different Ss was given the same procedure. Only the stimuli differed, so that he heard seven words in a list instead of six vowel sounds.

\section{Scoring}

The data were scored for tluree types of errors: intrusions, substitutions, and omissions. An intrusion error occurred when S reported a sound that was not presented in the list on that trial. A substitution error occurred when $S$ reported a sound that was in the presented list, but was reported in the wrong position. An omission error occurred when the S responded "blank." The scores for these three types of errors were combined to yield two 

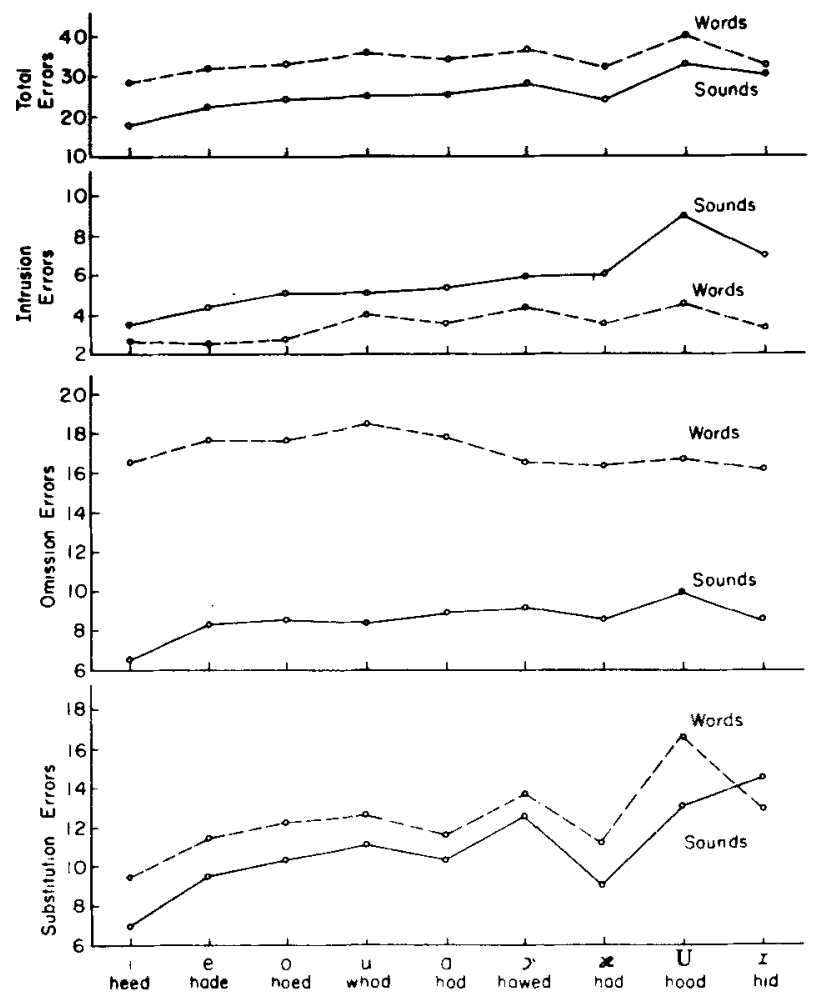

Fig. 1. Percentage of errors in recall of sounds alone, and sounds in words, summed over 50 Ss each. The four parts of the figure refer to total errors and to intrusions, omissions, and substitutions separately.

more error measures: total errors, the sum of the intrusions, substitutions, and omissions; and intrusions plus substitutions combined. One judge scored all recordings of Ss' responses. Several tapes were selected at random and scored for each error category by two other judges. There were no discrepancies in scoring.

\section{RESULTS}

Figure 1 presents the results for the sounds and for the words for each type of error. An analysis of variance showed that for both types of stimuli and each type of error, significant differences ( $p<.01$ in all cases) were found among the nine stimuli. Thus all eight curves shown in Fig. 1 had significant deviations from the horizontal. Further, for none of these curves was there any significant interaction between ease of recall and the type of stimuli. Thus, vowels presented alone had the same error patterns as vowels presented in words; the context of the sound did not affect the recall.

To determine the characteristics of the sounds which lead to differential errors, all intrusion and substitution errors were analyzed. Table 1 shows for each sound that was presented and Table 2 shows for each word that was presented the sound or the word that was recalled, summed over all Ss. Thus, the top row in Table 1 and Table 2, respectively, contains the number of times the item was recalled correctly. All other entries are the items incorrectly recalled when the particular sound or word was presented. Thus, summing over the $50 \mathrm{Ss}$ in the sound condition, when the sound /i/ was presented, it was incorrectly recalled as /a/ 104 times, as /e/ 89 times, and so forth. (Omission errors are not included since no way is available to determine what sound would have been substituted when S reported "blank." For this reason, the sum of all the errors plus the correct responses does not sum to the total possible score-2400 and 2800 for the sounds alone and sounds in words, respectively.)

Tables 1 and 2 are open to response bias in two different ways. A response which is produced erroneously very frequently will
Table 1.

Rank Order Intrusion Data for the Sound Alone Condition.

Numbers in cells refer to the frequency of intrusions

and substitutions, summed over $50 \mathrm{Ss}$, and

48 times each sound was presented.

\begin{tabular}{|c|c|c|c|c|c|c|c|c|c|}
\hline $\begin{array}{l}\text { Sound } \\
\text { presented }\end{array}$ & $\mid \mathrm{i} /$ & $|e|$ & $10 /$ & $|u|$ & $\mid a /$ & וכן & /ae/ & $/ \mathrm{U} /$ & /I/ \\
\hline $\begin{array}{l}\text { Recalled } \\
\text { correctly }\end{array}$ & $\begin{array}{c}\text { li/ } \\
1569\end{array}$ & $\begin{array}{c}\mid \mathrm{e} / \\
1277\end{array}$ & $\begin{array}{c}10 / \\
1204\end{array}$ & $\begin{array}{c}\text { w/ } \\
1195\end{array}$ & $\begin{array}{c}\mid \mathrm{a} / \\
1172\end{array}$ & $\begin{array}{l}\mid \supset / \\
1569\end{array}$ & $\begin{array}{l}/ 2 \mathrm{e} / \\
1046\end{array}$ & $\begin{array}{l}/ U / \\
802\end{array}$ & $\begin{array}{l}11 / \\
905\end{array}$ \\
\hline \multirow{10}{*}{ 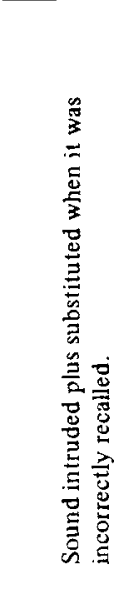 } & $\begin{array}{l}/ \mathrm{a} / \\
104\end{array}$ & $\begin{array}{l}\text { /i/ } \\
137\end{array}$ & $\begin{array}{l}\mid \mathrm{a} / \\
168\end{array}$ & $\begin{array}{l}|\supset| \\
290\end{array}$ & $\begin{array}{l}/ 0 / \\
181\end{array}$ & $\begin{array}{c}\text { /ae/ } \\
90\end{array}$ & $\begin{array}{l}\mid \supset / \\
352\end{array}$ & $\begin{array}{l}\mid \mathrm{a} / \\
352\end{array}$ & $\begin{array}{l}\mid \mathrm{e} / \\
309\end{array}$ \\
\hline & $\begin{array}{l}\langle\mathrm{e} / \\
89\end{array}$ & $\begin{array}{l}\mid \mathrm{u} / \\
136\end{array}$ & $\begin{array}{l}/ \mathrm{ae} / \\
133\end{array}$ & 999 & & $\begin{array}{l}/ \mathrm{u} / \\
89\end{array}$ & $\begin{array}{l}/ u / \\
146\end{array}$ & $\begin{array}{l}/ I / \\
167\end{array}$ & $\begin{array}{c}/ \mathrm{i} / \\
225\end{array}$ \\
\hline & $\begin{array}{l}11 / \\
77\end{array}$ & $\begin{array}{l}/ \mathbf{I} / \\
88\end{array}$ & $\begin{array}{l}\mid e / \\
103\end{array}$ & $\begin{array}{l}1 \mathrm{ae} / \\
77\end{array}$ & $\begin{array}{l}/ \mathrm{i} / \\
147\end{array}$ & $\begin{array}{l}/ \mathrm{e} / \\
44\end{array}$ & $\begin{array}{l}10 \mid \\
142\end{array}$ & $\begin{array}{l}10 / \\
154\end{array}$ & $\begin{array}{l}/ \mathrm{U} / \\
136\end{array}$ \\
\hline & $\begin{array}{l}/ \mathrm{U} / \\
58\end{array}$ & $\begin{array}{l}10 / \\
87\end{array}$ & $\begin{array}{l}1 \supset 1 \\
83\end{array}$ & $\begin{array}{l}10 / \\
74\end{array}$ & $\begin{array}{l}/ \mathrm{e} / \\
69\end{array}$ & $\begin{array}{l}10 / \\
37\end{array}$ & $\begin{array}{r}. / a / \\
66\end{array}$ & $\begin{array}{l}/ \mathrm{u} / \\
106\end{array}$ & $\begin{array}{l}/ \mathrm{u} / \\
129\end{array}$ \\
\hline & |כ| & |D| & $/ \mathrm{U}$ & 14 & $\supset$ & 71 & & /ae/ & $\mid \mathrm{a} /$ \\
\hline & 57 & $1-1$ & (1) & & 68 & & & 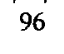 & 91 \\
\hline & $\begin{array}{l}10 / \\
51\end{array}$ & $\begin{array}{l}1 \mathrm{a} / \\
65\end{array}$ & $\begin{array}{l}\mid \mathrm{u} / \\
82\end{array}$ & $\begin{array}{l}/ 1 / \\
63\end{array}$ & $\begin{array}{l}\mid \mathrm{lu} / \\
64\end{array}$ & $\begin{array}{r}1 \mathrm{a} / \\
34\end{array}$ & $\begin{array}{l}/ \mathrm{U} \\
57\end{array}$ & $\begin{array}{l}1 D / \\
90\end{array}$ & $\begin{array}{c}121 \\
79\end{array}$ \\
\hline & $/ \mathrm{u} /$ & $\mid \mathrm{U} /$ & /il & 11 & /I/ & $|\mathrm{U}|$ & $\lambda_{i}$ & (i) & $10 /$ \\
\hline & 36 & 7 & 1.7 & & 57 & 29 & & 83 & 55 \\
\hline & $\begin{array}{c}\mid \mathrm{ae} / \\
30\end{array}$ & $\begin{array}{c}\mid \mathrm{ae} / \\
51\end{array}$ & $\begin{array}{l}11 / \\
40\end{array}$ & $\begin{array}{l}\text { JU/ } \\
45\end{array}$ & $\begin{array}{c}|\mathrm{ae}| \\
44\end{array}$ & $\begin{array}{l}\mid 1 / \\
23\end{array}$ & $\begin{array}{l}11 / \\
48\end{array}$ & $\begin{array}{l}|\mathrm{e}| \\
55\end{array}$ & $\begin{array}{r}\mid \mathrm{ae} / \\
44\end{array}$ \\
\hline
\end{tabular}

tend to show up in a high rank order position regardless of which sound was presented; and because omissions were not equal across columns, effectively the nine sounds were not presented an equal number of times. To control both of these sources of potential response bias, procedures similar to those of Wickelgren (1966) were undertaken. First, the error scores were corrected for overall frequency of errors. In Tables 3 and 4 the rank orders are based upon the size of the conditional probability of intruding plus substituting one sound for another. The conditional probabilities

Table 2

Tank Order Intrusion Data for the Sound in Word Condition. See Table 1.

Word
presented

\begin{tabular}{|c|c|c|c|c|c|c|c|c|c|}
\hline $\begin{array}{l}\text { Recalled } \\
\text { correctly }\end{array}$ & $\begin{array}{c}/ i / \\
1345\end{array}$ & $\begin{array}{c}1 \mathrm{e} / \\
1243\end{array}$ & $\begin{array}{c}10 / \\
1156 \\
\end{array}$ & $\begin{array}{c}/ \mathrm{u} / \\
1155\end{array}$ & $\begin{array}{c}1 \mathrm{a} / \\
1090\end{array}$ & $\begin{array}{c}1 \supset 1 \\
1145\end{array}$ & $\begin{array}{l}\text { /ae/ } \\
1037\end{array}$ & $\begin{array}{l}/ \mathrm{U} / \\
845\end{array}$ & $\begin{array}{c}/ 1 / \\
1209\end{array}$ \\
\hline \multirow{11}{*}{ 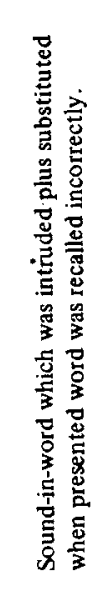 } & $\begin{array}{l}/ 1 / \\
148\end{array}$ & $\begin{array}{c}/ \mathrm{i} / \\
134\end{array}$ & 的 & & & & & & $|\mathrm{i}|$ \\
\hline & $\begin{array}{l}\mid \mathrm{e} / \\
98\end{array}$ & $\begin{array}{l}\mid u / \\
121\end{array}$ & $\begin{array}{l}\mid \mathrm{a} / \\
111\end{array}$ & & & & & & \\
\hline & $\begin{array}{r}\text { /a/ } \\
78\end{array}$ & 1 & /i & /ae/ & /i/ & & $/ \mathrm{a}$ & & u/ \\
\hline & $\mid \mathrm{u} /$ & $\operatorname{la}$ & $|\mathrm{e}|$ & (I) & $\pi$ & 101 & (]) & & $|e|$ \\
\hline & 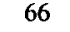 & & & & & & & & \\
\hline & $/ \mathrm{U} /$ & $/ \mathbf{I}$ & כつן & $\langle\mathbf{i} /$ & וכו & & & & 10 \\
\hline & 62 & & 85 & & 7 & & & & 75 \\
\hline & $\begin{array}{c}/ \mathrm{ae} / \\
62\end{array}$ & $\begin{array}{l}121 \\
73\end{array}$ & $\begin{array}{l}/ \mathrm{U} / \\
85\end{array}$ & $\begin{array}{r}10 / \\
72\end{array}$ & $|\mathrm{e}|$ & $\begin{array}{c}/ \mathrm{a} / \\
66\end{array}$ & & 10 & $\begin{array}{l}|\supset| \\
67\end{array}$ \\
\hline & $\mathrm{o}$ & $/ \mathbf{a}$ & $/ \mathbf{I}$ & $\mid \mathrm{a} /$ & $/ \mathbf{u} /$ & ii & $\mid \mathbf{e}$ & & 101 \\
\hline & 50 & & & & & & & & \\
\hline & |D/ & IU/ & $/ \mathrm{u} /$ & $\mid \mathrm{U} /$ & $\underset{52}{\mid \mathrm{ae} /}$ & $/ \mathrm{U} /$ & $/ \mathrm{U} /$ & $\begin{array}{c}1 \mathrm{~J} \\
66\end{array}$ & $\begin{array}{c}\text { /ae/ } \\
44\end{array}$ \\
\hline
\end{tabular}


Table 3

Rank Order of Intrusion Errors for Each Presented Sound in the Sound Alone Condition.

The rank order is based on

conditional probabilities.

\begin{tabular}{lccccccccc}
\hline $\begin{array}{l}\text { Sound } \\
\text { presented }\end{array}$ & $/ \mathrm{i} /$ & $/ \mathrm{e} /$ & $/ \mathrm{o} /$ & $/ \mathrm{u} /$ & $/ \mathrm{a} /$ & $\mathrm{J} /$ & $/ \mathrm{ae} /$ & $/ \mathrm{U} /$ & $/ \mathrm{J} /$ \\
\hline Rank & $\mathrm{a}$ & $\mathrm{i}$ & $\mathrm{a}$ & $\mathrm{J}$ & $\mathrm{o}$ & $\mathrm{ae}$ & $\supset$ & $\mathrm{a}$ & $\mathrm{e}$ \\
ordered & .2071 & .1974 & .2178 & .3722 & .2302 & .2362 & .3805 & .3191 & .2893 \\
intrusion & $\mathrm{e}$ & $\mathrm{u}$ & $\mathrm{ae}$ & $\mathrm{e}$ & $\mathrm{U}$ & $\mathrm{u}$ & $\mathrm{u}$ & $\mathrm{l}$ & $\mathrm{j}$ \\
errors & .1773 & .1959 & .1725 & .1271 & .1984 & .2336 & .1578 & .1514 & .2107 \\
& $\mathrm{I}$ & $\mathrm{I}$ & $\mathrm{e}$ & $\mathrm{ae}$ & $\mathrm{i}$ & $\mathrm{e}$ & $\mathrm{o}$ & $\mathrm{o}$ & $\mathrm{U}$ \\
& .1534 & .1268 & .1335 & .0988 & .1870 & .1155 & .1535 & .1396 & .1273 \\
& $\mathrm{U}$ & $\mathrm{o}$ & $\mathrm{J}$ & $\mathrm{o}$ & $\mathrm{e}$ & $\mathrm{o}$ & $\mathrm{a}$ & $\mathrm{u}$ & $\mathrm{u}$ \\
& .1155 & .1254 & .1077 & .0950 & .0878 & .0971 & .0714 & .0961 & .1208 \\
& $\supset$ & $\supset$ & $\mathrm{U}$ & $\mathrm{i}$ & $\supset$ & $\mathrm{i}$ & $\mathrm{e}$ & $\mathrm{ae}$ & $\mathrm{a}$ \\
& .1135 & .0980 & .1064 & .0950 & .0865 & .0919 & .0638 & .0870 & .0852 \\
& 0 & $\mathrm{a}$ & $\mathrm{u}$ & $\mathrm{I}$ & $\mathrm{u}$ & $\mathrm{a}$ & $\mathrm{U}$ & $\supset$ & $\supset$ \\
& .1016 & .0937 & .1064 & .0809 & .0814 & .0892 & .0616 & .0816 & .0740 \\
& $\mathrm{u}$ & $\mathrm{U}$ & $\mathrm{i}$ & $\mathrm{a}$ & $\mathrm{I}$ & $\mathrm{U}$ & $\mathrm{i}$ & $\mathrm{i}$ & $\mathrm{o}$ \\
& .0717 & .0893 & .1038 & .0732 & .0725 & .0761 & .0595 & .0752 & .0515 \\
& $\mathrm{ae}$ & $\mathrm{ae}$ & $\mathrm{I}$ & $\mathrm{U}$ & $\mathrm{ae}$ & $\mathrm{I}$ & $\mathrm{I}$ & $\mathrm{e}$ & $\mathrm{ae}$ \\
.0598 & .0735 & .0519 & .0578 & .0560 & .0604 & .0519 & .0499 & .0412 \\
\hline & & & & & & & &
\end{tabular}

were obtained by dividing each raw score by the total number of intrusions and substitutions for that presented sound.

The second procedure requires that the structures of Tables 3 and 4 be reversed. Rather than determining for each sound presented the order of frequency of intrusions plus substitutions made when the $S$ reported the wrong sound, Tables 5 and 6 display, for each sound erroneously reported, the sound most frequently presented, the next most frequent, down to the least frequent. For example, in Table 6, looking at the column where /i/ was the intruded sound we find that /i/ was given incorrectly in response to /I/ most often and in response to $/ \supset /$ least often. "This comparison within a column ... equates the response bias-that is, the S's bias to emit any particular sound, independent of its strength in short term memory" (Wickelgren, 1966, p. 396).

Table 5

The Rank Order of Presented Sounds by the Conditional Probability that the Intruded Sound Would Occur in its Pace. Data is from the sound alone condition.

\begin{tabular}{|c|c|c|c|c|c|c|c|c|c|}
\hline $\begin{array}{l}\text { Intruded } \\
\text { sound }\end{array}$ & $|i|$ & $|e|$ & 101 & $|u|$ & $|a|$ & וכן & $\mid \mathrm{ae} /$ & $/ \mathbf{U} /$ & $/ \mathrm{I} /$ \\
\hline \multirow{16}{*}{$\begin{array}{l}\text { Rank } \\
\text { order } \\
\text { of } \\
\text { presented } \\
\text { sounds }\end{array}$} & I & I & a & $\supset$ & $\mathbf{U}$ & ae & $\supset$ & a & i \\
\hline & .2107 & .2893 & .2302 & .2336 & .3191 & .3805 & .2362 & .1984 & .1534 \\
\hline & e & i & ae & e & o & $\mathbf{u}$ & o & I & $\mathrm{U}$ \\
\hline & .1974 & .1773 & .1535 & 1959 & .2178 & .3722 & .1725 & .1273 & .1514 \\
\hline & a & o & $\mathbf{U}$ & ae & i & i & $\mathbf{u}$ & i & e \\
\hline & .1870 & .1335 & .1396 & .1578 & .2071 & .1135 & .0988 & .1155 & .1268 \\
\hline & 0 & $\mathbf{u}$ & e & I & e & 0 & $\mathbf{U}$ & o & $\mathbf{u}$ \\
\hline & .1038 & .1271 & .1254 & .1208 & .0937 & .1077 & .0870 & .1064 & .0809 \\
\hline & $\mathbf{u}$ & כ & i & o & $\supset$ & e & e & e & $a$ \\
\hline & .0950 & .1155 & .1016 & .1064 & .0892 & .0980 & .0735 & .0893 & .0725 \\
\hline & $\supset$ & $\mathbf{a}$ & כ & $\mathbf{U}$ & I & $\mathbf{a}$ & $\mathrm{i}$ & $\supset$ & כ \\
\hline & .0919 & .0878 & .0971 & .0961 & .0851 & .0865 & .0598 & .0761 & .0604 \\
\hline & $\mathbf{U}$ & ae & $\mathbf{u}$ & a & u & $\mathbf{U}$ & $\mathbf{a}$ & ae & ae \\
\hline & .0751 & .0638 & .0950 & .0814 & .0732 & .0816 & .0560 & .0616 & .0519 \\
\hline & ae & $\mathbf{U}$ & I & $\mathbf{i}$ & ae & I & I & $\mathbf{u}$ & o \\
\hline & .0595 & .0499 & .0515 & .0717 & .0714 & .0740 & .0412 & .0578 & .0519 \\
\hline
\end{tabular}

The most important question is whether these patterns of errors can be predicted by any type of distinctive-feature system. It is important to note that distinctive-feature systems were designed to describe the components or features which make up a particular sound. As such they do not offer predictions as to the types of errors that would occur in short-term memory. Given a distinctive-feature system there are two types of prediction procedures which may be employed. The one used by Wickelgren was called "binary prediction," and the other may be referred to as "rank-order predictions."

Table 7 presents a traditional articulatory analysis (TAA, Pike, 1947) of the nine vowels used in this experiment. Using this distinctive-feature system we can jllustrate the types of predictions that are made using either binary predictions or rank-order predictions. In the binary-prediction method, using both height of tongue and front-back dimensions together we predict that those sounds closest to the presented sound will be intruded most often for that sound. For example, if /ae/ was the presented sound, the binary predictions would be that both /e/ and /a/ will be intruded more often that $/ \mathrm{i} /, / \mathrm{I} /, / \mathrm{J} /, / \mathrm{o} /, / \mathrm{u} /$, and $/ \mathrm{U} /$. Thus, this yields 12 binary predictions. Comparable predictions may then be generated for each sound, and then compared to the order of intrusion errors

Table 4

Rank Order of Intrusion Errors for Each Presented Sound-in-Word. The rank order is based on the conditional probabilities.

Word presented /hid/ /hed/ /hod/ /hud/ /had/ /hDd/ /haed/ /hUd/ /hId/

\begin{tabular}{lccccccccc}
\hline Rank & $\mathrm{I}$ & $\mathrm{i}$ & $\mathrm{ae}$ & $\mathrm{J}$ & $\mathrm{U}$ & $\mathrm{a}$ & $\mathrm{J}$ & $\mathrm{a}$ & $\mathrm{j}$ \\
ordered & .2434 & .2018 & .1894 & .2288 & .2365 & .2529 & .2900 & .2904 & .2845 \\
intrusion & $\mathrm{e}$ & $\mathrm{u}$ & $\mathrm{a}$ & $\mathrm{e}$ & $\mathrm{o}$ & $\mathrm{u}$ & $\mathrm{o}$ & $\mathrm{I}$ & $\mathrm{U}$ \\
errors & .1612 & .1822 & .1502 & .1530 & .1677 & .2423 & .1677 & .2135 & .1462 \\
& $\mathrm{a}$ & $\mathrm{o}$ & $\mathrm{i}$ & $\mathrm{a}$ & $\mathrm{i}$ & $\mathrm{e}$ & $\mathrm{a}$ & $\mathrm{o}$ & $\mathrm{u}$ \\
& .1283 & .1325 & .1272 & .1459 & .1514 & .1139 & .1200 & .1115 & .1292 \\
& $\mathrm{u}$ & $\mathrm{a}$ & $\mathrm{e}$ & $\mathrm{I}$ & $\mathrm{I}$ & $\mathrm{o}$ & $\mathrm{u}$ & $\mathrm{i}$ & $\mathrm{e}$ \\
& .1086 & .1114 & .1191 & .1216 & .1276 & .0993 & .1144 & .1115 & .1266 \\
& $\mathrm{U}$ & $\mathrm{I}$ & $\supset$ & $\mathrm{i}$ & $\supset$ & $\mathrm{I}$ & $\mathrm{i}$ & $\mathrm{ae}$ & $\mathrm{a}$ \\
& .1020 & .1114 & .1150 & .1173 & .0901 & .0900 & .0867 & .0712 & .0979 \\
& $\mathrm{ae}$ & $\supset$ & $\mathrm{U}$ & $\mathrm{o}$ & $\mathrm{e}$ & $\mathrm{a}$ & $\mathrm{l}$ & $\mathrm{e}$ & $\supset$ \\
& .1020 & .1099 & .1150 & .1030 & .0851 & .0874 & .0822 & .0702 & .0875 \\
& $\mathrm{o}$ & $\mathrm{ae}$ & $\mathrm{I}$ & $\mathrm{a}$ & $\mathrm{u}$ & $\mathrm{i}$ & $\mathrm{e}$ & $\mathrm{u}$ & $\mathrm{o}$ \\
.0822 & .0964 & .0934 & .0730 & .0763 & .0768 & .0700 & .0683 & .0705 \\
& $\supset$ & $\mathrm{U}$ & $\mathrm{u}$ & $\mathrm{U}$ & $\mathrm{ae}$ & $\mathrm{U}$ & $\mathrm{U}$ & $\supset$ & $\mathrm{ae}$ \\
& .0724 & .0482 & .0907 & .0572 & .0651 & .0371 & .0689 & .0635 & .0574 \\
& & & & & & & & &
\end{tabular}

found. If significantly more than half of the predictions are correct then the distinctive-feature theory being tested could be said to predict the pattern of errors.

In the rank-order predictions, the rank order of errors is correlated with the number of features each of the intruded sounds have in common with the presented sound. Thus, in the case when $/ \mathrm{ae} /$ is presented the rank-order predictions say that the order of errors will be $/ \mathrm{e} / / \mathrm{a} />/ \mathrm{J} / / \mathrm{i} / / \mathrm{l} />/ \mathrm{o} />/ \mathrm{u} /$ and $/ \mathrm{U} /$.

While the rank-order prediction method is more powerful, in that it can predict the entire ordering of errors, the binary-prediction method allows a test of the relative effect of each feature dimension, within the feature analysis, independent of the other dimensions in that theory. For example, in TAA (see Table 7), we can test binary predictions that are generated by (1) front-backness of the tongue, (2) relative height of the tongue, and (3) dimensions (1) and (2) together. The test of individual dimensions appears fruitful since there is no way to assess the relative strength or validity of any dimension in short-term memory, on a priori grounds.

These two procedures obviously generate a different number of predictions. In addition, these predictions will vary, depending 
Table 6

The Rank Order of Presented Sounds by the Conditional Probability that the Intruded Sound Would Occur in its Place. Data is from the sound in-word condition.

Intruded /hid//hed//hod/ /hud/ /had/ /hつd/ /haed/ /hUd/ /hId/

I i a J $\quad \begin{array}{llllll} & \text { ae } & \supset & \text { a } & \text { i }\end{array}$

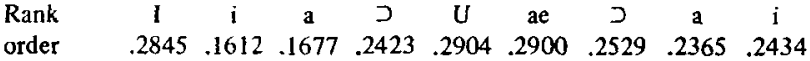

$\begin{array}{llllllllll}\text { presented } & \text { e } & \mathbf{u} & \text { ae } & \text { e } & \text { o } & \text { u } & \text { o } & \text { l } & \text { U }\end{array}$ sounds

\begin{tabular}{|c|c|c|c|c|c|c|c|c|}
\hline $\begin{array}{l}\text { a } \\
514\end{array}$ & $\begin{array}{c}1 \\
.1266\end{array}$ & $\begin{array}{c}\mathrm{e} \\
.1325\end{array}$ & $\begin{array}{c}I \\
.1292\end{array}$ & $\begin{array}{c}\mathrm{i} \\
.1283\end{array}$ & $\begin{array}{c}0 \\
.1150\end{array}$ & $\begin{array}{c}u \\
.1459\end{array}$ & $\begin{array}{c}0 \\
.1150\end{array}$ & $\begin{array}{c}\mathrm{a} \\
.1276\end{array}$ \\
\hline $\begin{array}{c}0 \\
272\end{array}$ & $\begin{array}{c}0 \\
.1191\end{array}$ & $\begin{array}{c}\mathrm{U} \\
.1115\end{array}$ & $\begin{array}{c}\text { ae } \\
.1144\end{array}$ & $\begin{array}{c}\text { ae } \\
.1200\end{array}$ & $\begin{array}{c}\mathrm{e} \\
.1099\end{array}$ & $\begin{array}{c}\mathrm{i} \\
.1020\end{array}$ & $\begin{array}{c}\mathrm{i} \\
.1020\end{array}$ & $\begin{array}{c}u \\
.1216\end{array}$ \\
\hline $\begin{array}{c}\mathrm{u} \\
1173\end{array}$ & $\begin{array}{c}\supset \\
.1139\end{array}$ & $\stackrel{u}{u} .1030$ & $\begin{array}{c}\mathrm{i} \\
.1086\end{array}$ & $\begin{array}{c}\mathrm{e} \\
.1114\end{array}$ & $\begin{array}{c}a \\
.0901\end{array}$ & $\begin{array}{c}\mathrm{e} \\
.0964\end{array}$ & $\begin{array}{c}\mathrm{ae} \\
.0689\end{array}$ & $\begin{array}{c}\mathrm{e} \\
.1114\end{array}$ \\
\hline $\begin{array}{c}\mathrm{U} \\
1115\end{array}$ & $\begin{array}{c}\mathrm{a} \\
.0851\end{array}$ & $\begin{array}{c}\supset \\
.0993\end{array}$ & $\begin{array}{c}0 \\
.0907\end{array}$ & $\begin{array}{c}\mathrm{I} \\
.0979\end{array}$ & $\begin{array}{c}I \\
.0875\end{array}$ & $\begin{array}{c}\mathrm{U} \\
.0712\end{array}$ & $\begin{array}{c}\mathrm{u} \\
.0572\end{array}$ & .0934 \\
\hline $\begin{array}{c}\text { ae } \\
0867\end{array}$ & $\begin{array}{c}\mathrm{U} \\
.0702\end{array}$ & $\begin{array}{c}\mathbf{i} \\
.0822\end{array}$ & $\begin{array}{c}\mathrm{a} \\
.0763\end{array}$ & $\begin{array}{c}\supset \\
.0874\end{array}$ & $\begin{array}{c}\mathrm{i} \\
.0724\end{array}$ & $\begin{array}{c}\mathrm{a} \\
.0651\end{array}$ & $\begin{array}{c}\mathrm{e} \\
.0482\end{array}$ & .0900 \\
\hline$\stackrel{\supset}{0768}$ & $\begin{array}{c}\text { ae } \\
0700\end{array}$ & $\begin{array}{c}1 \\
.0705\end{array}$ & $\begin{array}{c}\mathrm{U} \\
0635\end{array}$ & $\begin{array}{c}\mathbf{u} \\
0730\end{array}$ & $\begin{array}{c}\mathbf{U} \\
.0635\end{array}$ & $\begin{array}{c}1 \\
0574\end{array}$ & $\stackrel{\supset}{.0371}$ & 082 \\
\hline
\end{tabular}

upon the type of distinctive feature system used to describe the sounds. In addition to the TAA (Table 7), two other systems are tested. Table 8 presents the Conventional Phonetic Alphabet (CPA). This system differs from the TAA in that $/ a /$ is classified in CPA as a low-back vowel, instead of a low-central vowel. For example, using CPA, the 15 binary predictions for /ae/ would be that each of $/ e /, \mid a /$, and $/ \supset /$ will exceed in errors each of $/ i /, / I /$, $/ \mathrm{o} / \mathrm{/ \textrm {u }} /$, and $/ \mathrm{U} /$

A third distinctive-feature system is tested (Halle, 1962) in this experiment (see Table 9). In Halle's classification, /i/ and / $/$ / are equivalent to $/ \mathrm{H} /$ and $/ U /$, respectively, as designated in the present experiment. Furthermore, Halle does not include an analysis for the sounds $/ i /$ and $/ u /$. Presumably, these sounds differ from $/ 1 /$ and $/ U /$, respectively, along a tense/lax dimension, with all other feature specifications being the same. In addition, /e/ in Halle's system would be a lax variant of $/ e /$ as presented in this experiment. In this system the feature proximity of sounds is determined by the number of dimensions in which the two sounds have the same sign (when using all dimensions), or by the sounds which have the same sign on any given dimension (when testing individual dimensions). Predictions can be generated based on the six sounds Halle classified which are identical to sounds used in our experiment (see Table 10) or based on all nine sounds (see Table 11). These latter predictions assume that the tense/lax dimension is not critical in encoding, and thus yield identical classifications for $/ \mathrm{i} / / \mathrm{H} /$, and for $/ \mathrm{u} / \mathrm{U} /$. Thus in Table $11, / \mathrm{i} /$ is most similar to $/ 1 /$, next most similar to $/ \mathrm{e} /$, but has no features in common with $\supset /$.

To test the rank order predictions, the corresponding columns of Tables 7,8 , and 11 were correlated with the respective columns of Tables 5 and 6 (those that had been corrected for response

Table 8

The Articulatory Placement of Vowels Used in this Experiment, According to the Conventional Phonetic Alphabet (CPA)

\begin{tabular}{lcc}
\hline & Front & Back \\
\hline Hiigh & $\mathrm{i}$ & $\begin{array}{c}\text { u } \\
\mathrm{U}\end{array}$ \\
\hline Mid & $\mathrm{I}$ & $\mathrm{o}$ \\
\hline & $\mathrm{e}$ & $\supset$ \\
\hline
\end{tabular}

bias). Nine correlations were obtained for each comparison, and these were averaged to find a mean correlation between the predicted order of errors and the actual pattern of errors obtained. None of the mean correlations differed significantly from zero. Thus, using rank order predictions, there appears to be no overall relationship between the pattern of errors predicted by any of the three distinctive-feature systems and the pattern of errors obtained for the sounds in isolation or sounds embedded in words.

Since the rank order predictions for the distinctive-feature systems failed to predict the pattern of errors found, these systems were tested using binary predictions. Table 12 presents the results of these analy ses.

Inspection of Table 12 shows, (1) that when using the TAA, the dimension of tongue height yields the greatest percentage of correct binary predictions; $54 \%$ for the sound alone, and $60 \%$ for the sound in word, and (2) that when using the CPA, both dimensions together yield the greatest percentage of correct binary predictions for the sound alone condition, $58 \%$, and the dimension of tongue height yields the great percentage of correct predictions for the sound-in-word condition, 60\%. In Wickelgren's (1965) experiment, using the CPA, the dimension of tongue height

Table 7

The Articulatory Placement of Vowels Used in this Experiment, According to a Traditional Articulatory Analysis (TAA) (Pike, K. L. Phonemics: A Technique for Reducing Languages to Writing. Ann Arbor: University of Michigan Press, 1947. P. 5.)

\begin{tabular}{|c|c|c|c|c|}
\hline & & Front & Central & Back \\
\hline \multirow{2}{*}{ High } & close & $\mathbf{i}$ & & $\mathbf{u}$ \\
\hline & open & 1 & & $\mathbf{U}$ \\
\hline \multirow{2}{*}{ Mid } & close & e & & 0 \\
\hline & open & & & \\
\hline \multirow{2}{*}{ Low } & close & $x$ & & כ \\
\hline & open & & a & \\
\hline
\end{tabular}

predicted his intrusion data with $75 \%$ accuracy, the front-backness of the tongue with $100 \%$ accuracy, and both dimensions together with $97 \%$ accuracy. Using Wickelgren's results as a baseline, we may thus conclude that neither the binary predictions for TAA nor CPA were adequate to predict the errors in short-term memory for this experiment

In Halle's (1962) system only four dimensions were presented as critical and nonredundant to explain the feature composition of the vowels. Since Halle's system did not predict our data using rank order predictions, we decided to test only those vowels which are the same in Halle's matrix and this experiment $(/ 1 /, / a e /, / a /$, $/ \mathrm{U} /, / \mathrm{O} / \mathrm{D} / \mathrm{l}$. Inspection of Table 12 shows that the diffuse dimension yields the greatest percentage of correct binary predictions for both the sound condition, $78 \%$, and the word condition, $78 \%$. Although this percentage is relatively high as compared to all other analyses tried, it still falls far short of the perfect accuracy with which Wickelgren (1965) could predict his intrusion data using the front-back dimension of CPA.

Two other characteristics of the sounds were examined to see if they would predict the errors. The first divides the sounds in isolation according to the ease with which they can be labelled. Looking again at Fig. 1, the nine sourds along the abscissa are ordered in terms of labelling, with the first three on the left being easy to label, and the last three on the right being very difficult to label. It is clear that ease of labelling is highly related to overall difficulty in recalling the sounds alone and the sounds in words. The labelling classification is significant at the $p<.01$ for both sounds and words, for each of the error scores.

The second test compares the overall error rates with the frequency of usage of the words. A brief inspection shows that there is no relationship, which is borne out by an analysis of variance. Embedding a given sound in a frequent word does not increase its chances of being recalled.

As a check on the reliability of the rank order of errors, and as a 
Table 9

The Distinctive Feature Composition of Some Vowels in our Experiment as Suggested by Halle. Only Those Distinctive Feature Dimensions are Presented Which Differentiate the Vowels

\begin{tabular}{lccccccr}
\hline & $\mathrm{i}$ & $\mathrm{e}$ & $\mathrm{a}$ & $\mathrm{a}$ & $\mathrm{u}$ & $\mathrm{o}$ & $\supset$ \\
\hline Flat & - & - & - & - & + & + & + \\
Compact & - & - & + & + & - & - & + \\
Diffuse & + & - & - & - & + & - & - \\
Grave & - & - & - & + & + & + & +
\end{tabular}

Note: Halle's /i/ and /u/ refers to our sounds $/ I /$ and $/ U /$. Further. /e/ in Halle's system is a lax variant of the sound used in our experiment.

test of the effects of embedding the sounds in words, comparable correlations were computed between the corresponding columns of Tables 1 and 2, 3 and 4 , and 5 and 6 . The means of the rank order correlations were +.64 (with a range from +.38 to +.79 ), $+.64(+.32$ to +.89$)$, and $+.69(+.57$ to +.86$)$, respectively, all significantly $(\mathrm{p}<.01)$ different from zero. Thus, while the distinctive feature systems do not predict the patterning of errors with great accuracy, those patterns are not only reliably stable, but very similar for the two conditions. Thus, the order in which sounds will be confused with one another does not change when the sounds are embedded in words. This conclusion with respect to intrusion and substitution errors is supported for overall recall performance as well (see Fig. 1).

\section{DISCUSSION}

Four findings have been reported: (1) Both overall recall and the patterns of substitution and intrusion errors are virtually identical for sounds in isolation and for sounds in words; (?) three distinctive-feature analyses will not predict the pattern of errors for sounds in isolation or sounds in words, whether a rank order prediction method or binary prediction method is employed; (3) the ease of labelling the sounds alone will accurately predict overall recall performance both for sounds alone, and more surprisingly for the sounds in words: and, finally, (4) the frequency of the usage of the words is unrelated to any performance measure.

The finding regarding ease of labelling is difficult to accept on face value. It implies that sounds are labelled as sounds, even when they are part of a word. Thus, when the word "hoed" is heard. the sound $/ 0 /$ is extracted, labelled with the letter "O," and rehearsed in this form. At report, the sound is recoded back to the word. However, no S ever reported the sound independently of the word in the word condition. If the above encoding process is actually occurring, numerous errors of this kind should have been found.

\section{Table 11}

Predicted Rank Order Intrusion Errors for All Nine Sounds in This Experiment by Number of Features in Common (from Halle, 1962). Halle's Analysis does not Include a Feature Differentiation for $/ \mathrm{I} / \mathrm{vs} / \mathrm{i} /$, and $/ U /$ vs $/ \mathrm{u} /$

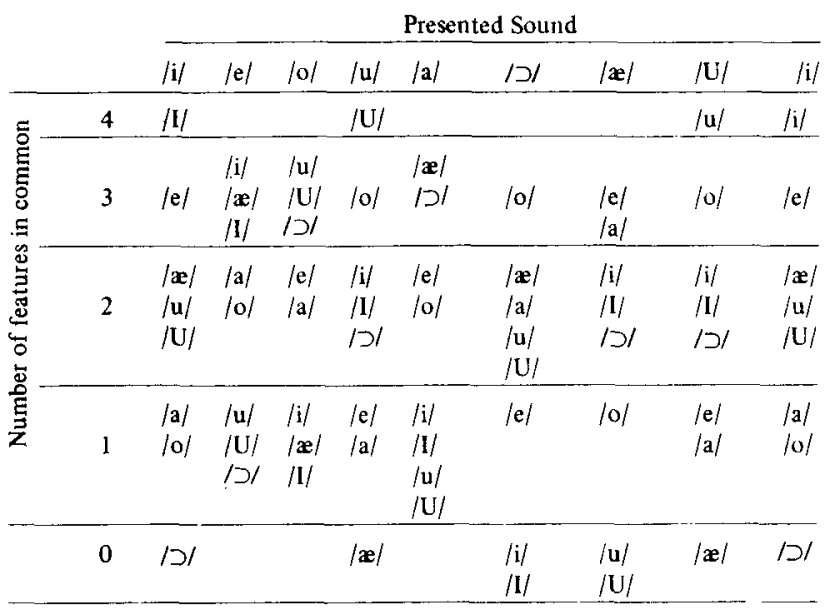

It is possible, however, that the nature of the task caused the sounds to be labelled as such in the word condition. In a trial sequence such as hood, hid, had, hoed, heed, hod, hawed, the consonant environment is constant and the vowel sound is the only part changing. This would make it easy for thy $S$ to attend only to the vowel sound, in which case labelling may be important. It is also possible that with repetition during rehearsal, the $\mathrm{S}$ may lose all sense of meaning, as a result of verbal satiation (Lambert \& Jakobovitz, 1960). Thus, while he may be able to repeat the word names, he does not know them. In this way, while a word context was provided for the vowel sounds, they may have been lost to the $S$ by the time he recalled the items, so that all effects of the context would be nullified. To the extent that this is true, it would account for the great similarity of the two conditions in the experiment, without implying that vowel sounds in isolation and vowel sounds in words are encoded in the same way. (To remove this objection, it would be necessary to use several different vowel environments, or use longer words, so that the critical vowel was not the only variation in the list.)

The above reasoning suggests that the labelling hypothesis may be acceptable, even though it predicts the recall of words as well as the recall of sounds in isolation. However, the labelling hypothesis does not predict or explain the pattern of intrusion and substitution entors shown in Tables 1 through 6 . If easily labelled sounds are recalled better, then we might expect some orderly pattern of errors. For example, we might predict that if a sound is forgotten, an easily labelled sound should be substituted. In this

Table 10

Predicted Rank Order Intrusion Errors by Number of Features in Common (from Halle, 1962). Only Those Sounds are Included Which are Identical in this Experiment and Halle's Analysis

\begin{tabular}{|c|c|c|c|c|c|c|c|}
\hline \multirow{5}{*}{ 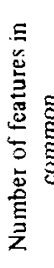 } & & \multicolumn{6}{|c|}{ Presented Sound } \\
\hline & & $10 /$ & $|a|$ & I & $|\mathbf{x}|$ & $|\mathrm{u}|$ & /I/ \\
\hline & S Three & $|\mathrm{U} / \mathrm{D}|$ & $\begin{array}{l}|\mathbf{x}| \\
|\mathrm{D}|\end{array}$ & $\begin{array}{l}/ \mathrm{a} / \\
/ \mathrm{u} / / \mathrm{o} /\end{array}$ & $|a|$ & $\begin{array}{l}101 \\
101\end{array}$ & \\
\hline & Two & $|0|$ & 101 & $|\mathbf{x}|$ & $\mid 1 / \mathrm{D}$ & (1) & $/ \mathbf{U} / \mathbf{x}$ \\
\hline & One & $|1 /| \mathbf{x} \mid$ & $/ 1 / / \mathbf{U} /$ & & 10 & $|a|$ & $|\mathrm{a} / \mathrm{/o}|$ \\
\hline & Zero & & & $/ \mathbf{I}$ & $/ \mathrm{U} /$ & $|\mathbf{x}|$ & J \\
\hline
\end{tabular}

case, we should expect the sounds witl English letter names to be recalled erroneously more often. Thus, the top rows in Tables 1 and 2 should have a concentration of $/ \mathrm{i} / \mathrm{e} / \mathrm{e}$ and $/ \mathrm{o} / \mathrm{O}$, the labelling might be specific to the sound, when a hard-to-label sound is forgotten, another liard-to-label sound should be substituted for it, and similarly for the easy-to-label sounds or vice versa. Analyzing the intrusion errors according to any of these assumptions fails to show any pattern of errors. Thus, labelling does not seem to predict the intrusion errors.

However, labelling does, indeed, produce a major effect and hence must be a relevant variable in some way. One possibility is that sounds that are easily labelled are most resistant to forgetting. This resistance due to labelling may be the result of better encoding into memory initially, or of superiority in rehearsal. In this way, ease of labelling will predict accuracy of recall. However, once a sound is forgotten, for whatever reason, other, as yet unidentified, factors will account for the substitution made in its place.

The results of this experiment concerning the inadequacy of a distinctive feature system to predict the intrusion errors found, are consistent with findings reported by Liberman, Cooper, Shankweiler, and Studdart-Kennedy (1967). They reported that whereas consonants are reconstructed or encoded as distinctive features in the sound strean (a finding also suggested by Cole, Haber, \& Sales, 1968), vowels under many conditions, are not. Thus, they argue that vowels may be perceived in much the same way as any complex non-speech sound. If vowels are initially perceived as sensory events having auditory qualities, a "naming", process would account for their encoding (Liberman, 1968). Thus, 
Table 12

The Percentage of Correct Binury Predictions for Three Feature Systems, Using a Shared Feature Hypothesis. Scores are Presented for both Experimental Conditions, Using Tables 5 and 6.

\begin{tabular}{|c|c|c|c|}
\hline \multirow[b]{2}{*}{ System } & \multirow[b]{2}{*}{ Dimension } & \multicolumn{2}{|c|}{$\begin{array}{l}\text { Per cent of correct } \\
\text { binary predictions }\end{array}$} \\
\hline & & Sound alone & sound-in word \\
\hline TAA & $\begin{array}{l}\text { (1) height of tongue } \\
\text { (2) Front-backness } \\
\text { (3) both (1) \& (2) }\end{array}$ & $\begin{array}{l}54 \% \\
48 \% \\
48 \% \\
\end{array}$ & $\begin{array}{l}60 \% \\
45 \% \\
52 \% \\
\end{array}$ \\
\hline CPA & $\begin{array}{l}\text { (1) height of tongue } \\
\text { (2) Front-backness } \\
\text { (3) both (1) \& (2) }\end{array}$ & $\begin{array}{l}54 \% \\
53 \% \\
58 \%\end{array}$ & $\begin{array}{l}60 \% \\
49 \% \\
58 \% \\
\end{array}$ \\
\hline Halle & $\begin{array}{l}\text { (1) Fht } \\
\text { (2) compact } \\
\text { (3) diffuse } \\
\text { (4) grave } \\
\text { (5) (1) \& (2) \& (3) \& (4) }\end{array}$ & $\begin{array}{l}28 \% \\
50 \% \\
78 \% \\
56 \% \\
38 \% \\
\end{array}$ & $\begin{array}{l}25 \% \\
55 \% \\
78 \% \\
41 \% \\
29 \%\end{array}$ \\
\hline
\end{tabular}

distinctive-feature systems should not predict the pattern of errors, and more nameable vowels should be remembered better-an explanation quite consistent with our findings.

The question still remains as to why a distinctive-feature model fails to predict the pattern of errors in this experiment, yet predicted errors in Wickelgren's (1965). It is obvious that the patterns are lawful and stable, as shown by the high correlations across conditions. Several observations can be advanced that might help to account for this failure. On the basis of Wickelgren's results with vowels, we assumed that those sounds which had the greatest number of features in common would be intruded most often for each other, either on one dimension or on all dimensions combined. This reasoning, most accurately called a shared feature hypothesis, was used for both binary and rank-order predictions. However, inspection of the results indicates that certain dimensions may be more important than others for encoding certain vowels and that these critical dimensions may not be the same for all vowels. Further, on a given dimension, a sound may be most often intruded by another sound not having that feature in common.

In order to check these findings, a post hoc analysis was made of the accuracy of the binary predictions for each sound in isolation, using Halle's (1962) distinctive-feature specification. In the result already reported, the percentage of correct binary predictions for each dimension was calculated on the sum of all vowels, this yielding a mean per cent score for that dimension. These results can be reexamined to determine: (1) what dimension best predicts each sound; (2) on that dimension, is a positive prediction most accurate (e.g., presented and intruded sound share that feature) or a negative prediction (e.g., presented and intruded sound do not share that feature); and (3) will predictions using different dimensions for each vowel increase the percentage of correct predictions. Since this is an ad hoc re-analysis, it was carried out only on the sound-in-isolation condition, and then tested on the word condition.

Table 13 presents the results of this inspection. Under each sound are listed those dimensions which best predict that sound. For example, in the sound condition under $/ 0 /$, the diffuse dimension predicts errors five out of six times correctly using a positive prediction. Yet note that the compact dimension predicts the errors for this sound equally well using a negative prediction. Likewise, for /ae/ the diffuse dimension will predict errors five out of six times correctly, using a positive prediction. However, the flat or grave dimension will predict errors $100 \%$ using a negative prediction. In this case, the flat dimension is most powerful since it discriminates between more sounds, thus, yielding six binary predictions as compared to four binary predictions to test on the grave dimension. Using this procedure, Halle's distinctive-feature system predicts the errors $93 \%$ of the time, for the sound in isolation condition. This analysis was then carried out on the word condition. For this condition $90 \%$ of the binary predictions were correct.

Inspection of Table 13 clearly suggests: (1) For differen vowels, different dimensions predict errors most accurately. (2) The prediction that might be most appropriate for a given dimension may be a negative as opposed to a positive prediction (3) There is a high degree of intercorrelation between the dimensions which best predicted a sound in each condition. (4) The per cent of accurate predictions approaches $100 \%$ when different dimensions are allowed to predict different sounds.

In Table 13, for some sounds, no dimension will perfectly predict the pattern of intrusion errors. A possible reason for this occurrence may lie in the stimuli used in this experiment. The nine vowel sounds used are rather similar to each other in terms of the maximum amount of variation available in distinctive-feature differentiation. Thus, $/ \mathrm{i} /, / \mathrm{I} / \mathrm{h}$, and $/ \mathrm{u} /, / \mathrm{U} /$ are almost identical, according to distinctive-feature analyses. Had more variation in sounds been presented, perhaps the correlations with the predictions would have been better. However, enough variation was present to generate very high correlations between conditions, so this, if anything, suggests that if the distinctive-feature model is correct, it is limited in power when stimuli are very similar. Further, if $/ u /$ and $/ U /$ are nearly identical, in reference to othe sounds, they should have very similar error patterns. However, our data showed quite different patterns for these "similar" sounds, and moreover, these patterns were the same in both conditions.

In the analyses we assumed that a tense/lax distinction was not critical (e.g., /u/ and / $U /$ would have the same feature matrix). Our results suggest that this assumption is untenable in some cases. Although this dimension may not be important when tense/lax variant discriminations are not forced (e.g., Wickelgren did not present any tense/lax variants in his experiment), it seems reasonable to suggest that this dimension may become critical and interact with other feature dimensions when two variants are presented in an encoding task (e.g., $/ \mathrm{u} /$ and $/ \mathrm{U} /$ ). According to Halle's analysis, two tense/lax variant groups were present in our experiment $(/ \mathrm{i} / / \mathbf{I} /$ and $/ \mathrm{u} / / \mathrm{U} /)$, while in the CPA, three variant groups (which are referred to as open/close variants) are present $(/ \mathrm{i} / / \mathrm{I} /, / \mathrm{u} / / \mathrm{U} /$, and $/ \mathrm{J} / / \mathrm{a} /)$. Even though these variants are not included in the preceding analysis (see Table 13), they were part of the stimuli and thus could have interacted with other stimuli in encoding, yielding a possible alteration in resultant intrusion errors. The occurrence of dimension interactions has been pointed out by Halle (1962); for example, all (+) compact sounds are (-) diffuse.

In order to check this hypothesis, a post hoc analysis was done using the CPA system (see Table 8) which Wickelgren found successful in predicting his data. Binary predictions were generated using both dimensions together. We then followed a procedure to adjust for stimulus bias (bias in this case refers to the tense/lax or open/close variation). After calculating the percentage of correct binary predictions for each sound, we looked at those sounds which were one of the three biased sets of stimuli. If one of the variants did not conform to the binary prediction, it was eliminated from the scoring. Using this procedure, it was noted that the percentage of correct binary predictions substantially increases for both conditions. Where $100 \%$ accuracy was not reached for a given sound, it always entailed those vowels which did not have a variant present in this experiment: $/ \mathrm{e} /, / \mathrm{ae} /, / \mathrm{o} /$. This post hoc analysis suggests that the tense/lax dimension (or open/close as it is referred to in CPA) was crucial for the Ss' coding in this experiment.

Some final considerations are warranted. While we assumed that the sounds would be pronounced correctly, many variants are possible which we did not score. Thus while $S$ was presented with /e/, he might have made a glide and pronounced it as /ei/ on his recall. The analysis of the responses taken from the tape recordings needed to make these scorings exceeded the resources of this study. This issue is important because we scored each response as if $S$ always responded with one of the nine presented sounds, and not with some variant. Thus, the variants do not count as errors. If variants are included, the distinctive-feature 
Table 13

A Chart of Thooe Dimemions Which Beat Predict the Intrusions, in Both the Sound Alone Condition and the Soundin-Wond Cosdition. Thea Dimencions are Taken from Halle's (1962) Diatinetive Feature System

\begin{tabular}{|c|c|c|c|c|c|c|}
\hline \multicolumn{7}{|c|}{ Sound alone condition } \\
\hline Positive predictions & Diffuse $5 / 6$ & Grave $6 / 6$ & $\begin{array}{l}\text { Compact } 5 / 6 \\
\text { Diffuse } 6 / 6\end{array}$ & Diffuse $5 / 6$ & Diffuse $3 / 4$ & Diffuse $4 / 4$ \\
\hline Negative predictions & Compact $5 / 6$ & $\begin{array}{l}\text { Compact } 5 / 6 \\
\text { Flat } 6 / 6 \\
\end{array}$ & & $\begin{array}{l}\text { Flat } 6 / 6 \\
\text { Grave 4/4 } \\
\end{array}$ & & \\
\hline Positive predictions & Diffuse $5 / 6$ & & $\begin{array}{l}\text { Compact } 5 / 6 \\
\text { Diffuse } 5 / 6\end{array}$ & Diffuse $5 / 6$ & Diffuse $3 / 4$ & $\begin{array}{l}\text { Compact } 5 / 6 \\
\text { Diffuse } 4 / 4\end{array}$ \\
\hline Negative predictions & Compact $5 / 6$ & Compact $5 / 6$ & & $\begin{array}{l}\text { Flat } 6 / 6 \\
\text { Grave } 4 / 4\end{array}$ & Flat $5 / 6$ & Grave $4 / 4$ \\
\hline
\end{tabular}

predictions would be changed slightly, and the predictive value of such analyses might be enhanced.

Furthermore, a vowel presented in isolation is not pronounced identically to the vowel appearing in a word. The context often exerts significant changes in the articulation. A given context could presumably make certain vowels more difficult to pronounce than others, due to the change in the vocal apparatus needed to shift from consonant to vowel to consonant. This also does not seem to be a large effect, and is partially called into question by the high correlation between the sound alone and the sound in word conditions. However, it is a potential one. Wickelgren (1965) avoided it by requiring Ss to write their responses rather than pronounce them. We are currently exploring such a change in design as well, even though we do not expect it to affect this aspect of the conclusions.

In summary, this study shows that when $S$ has to recall a list of sounds he has just heard, he will make errors based on his ease of labelling the sounds, differences which are presumably based on his past verbal language habits. Embedding the sounds in short words seems to have no effect on the ease of recall, even though the words differed greatly in frequency and meaningfulness. Finally, neither articulatory or acoustic distinctive-feature systems were able to predict the pattern of errors with great accuracy, at least within the limited range of sounds used. This suggests that the probability that a sound will be recalled is a function of the ease with which it can be labelled. However, once forgotten, neither labelling nor a distinctive-feature model in which all dimensions are equally weighted seems able to predict the highly lawful pattern of errors that was found. Post hoc analyses suggested that: (1) various distinctive-feature dimensions are not equally effective in their prediction of errors made to different sounds; (2) these dimensions that are critical are dependent upon the type of discriminations $S$ is forced to make in coding; and (3) negative predictions (as opposed to a positive, shared feature prediction) may be equally adequate for predicting intrusion errors in short-term memory.

\section{REFERENCES}

COLE, R. A., HABER, R. N., \& SALES, B. D. Mechanisms of aural encoding I. Perception \& Psychophysics, 1968, 3, 281-284.

HALLE, M. Phonology in a generative grammar. Word, 1962, 18, 54-72.

LAMBERT, W. E., \& JAKOBOVITZ; L. A. Verbal Satintion and changes in the intensity of meaning. Joumal of Experimental Psychology, 1960, 60, 376-383.

LIBERMAN, A. M. Personal communication. 1968.

LIBERMAN, A. M., COOPER, F. S., SHANKWEILER, D. P., \& STUDDERT-KENEDDY, M. Perception of the speech code. Psychological Review, 1967, 74, 431-461.

PIKE, K. L. Phonemics: A technique for reducing languages to writing. Ann Arbor: University of Michigan Press, 1947. P. 5.

THORNDIKE, E. L., \& LORGE, I. A teachers' wondbook of 30,000 words. New York: Teachers College, 1944.

WCKELGREN, W. A. Distinctive features and errors in short-term memory for English vowels. Journal of the Acoustical Society of America, 1965, 38, 583.588.

WICKELGREN, W. A. Distinctive features and errors in short-term memory for English consonants. Journal of the Acoustical Society of America, $1966,39,388-398$.

\section{NOTES}

1. This research was supported in part by an award to the last author from an Undergraduate Research Participation Grant of the National Science Foundation to the University of Rochester, and by a research grant to the second author from the United States Public Health Service, MH-10753, and a research grant from the National Science Foundation, GB 5901. We would like to thank Barbara Herr, Linda Jaeger, and Mary McDermott for thoir assistance in this project. The authors also wish to express their appreciation to A. M. Liberman and Wayne A. Wickelgren for excellent comments on an earlier draft of this paper.

2. Address: Department of Psychology, University of Rochester, Rochester, N. Y. 14627.

3. Now at the University of California at Riverside.

(Accepted for publication August 9, 1968.) 